This item was submitted to Loughborough's Research Repository by the author.

Items in Figshare are protected by copyright, with all rights reserved, unless otherwise indicated.

\title{
A nanometre-scale fibre-to-matrix interface characterization of an ultrasonically consolidated metal matrix composite
}

PLEASE CITE THE PUBLISHED VERSION

PUBLISHER

(C) IMechE / Professional Engineering Publishing

VERSION

VoR (Version of Record)

LICENCE

CC BY-NC-ND 4.0

\section{REPOSITORY RECORD}

Friel, Ross J., and Russell A. Harris. 2019. "A Nanometre-scale Fibre-to-matrix Interface Characterization of an Ultrasonically Consolidated Metal Matrix Composite”. figshare. https://hdl.handle.net/2134/6204. 
This item was submitted to Loughborough's Institutional Repository (https://dspace.lboro.ac.uk/) by the author and is made available under the following Creative Commons Licence conditions.

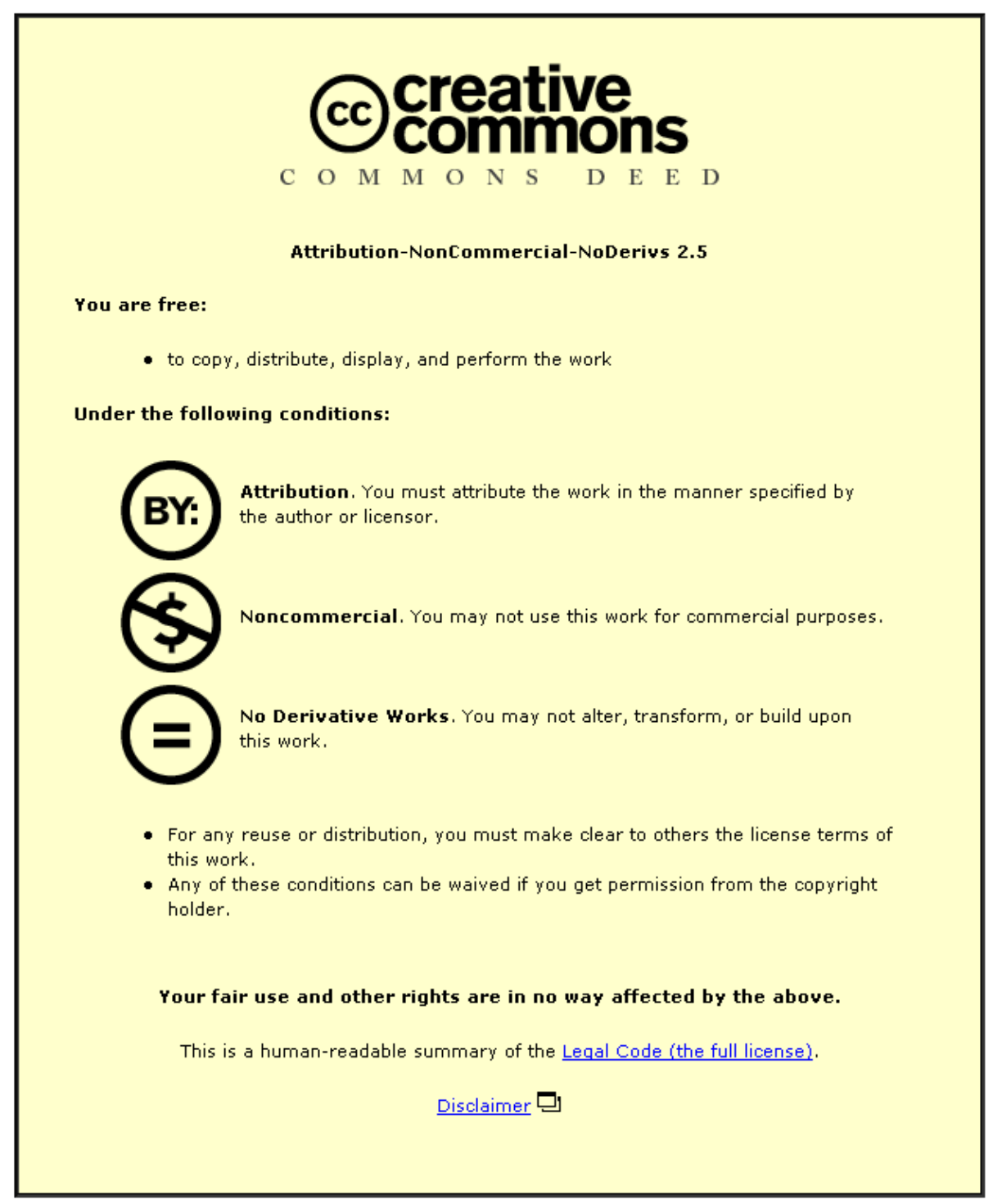

For the full text of this licence, please go to: http://creativecommons.org/licenses/by-nc-nd/2.5/ 


\title{
A nanometre-scale fibre-to-matrix interface characterization of an ultrasonically consolidated metal matrix composite
}

\author{
R J Friel* and R A Harris \\ Wolfson School of Mechanical and Manufacturing Engineering, Loughborough University, Loughborough, \\ Leicestershire, UK
}

The manuscript was received on 19 March 2009 and was accepted after revision for publication on 6 October 2009.

DOI: 10.1243/14644207JMDA268

\begin{abstract}
Future 'smart' structures have the potential to revolutionize many engineering applications. One of the possible methods for creating smart structures is through the use of shape memory alloy (SMA) fibres embedded into metal matrices. Ultrasonic consolidation (UC) allows the embedding of SMAs into metal matrices while retaining the SMA's intrinsic recoverable deformation property. In this work, NiTi SMA fibres were successfully embedded into an Al 3003 (0) matrix via the UC layer manufacturing process. Initially the plastic flow of the Al matrix and the degree of fibre encapsulation were observed using optical microscopy. Then microstructural grain and sub-grain size variation of the $\mathrm{Al} 3003$ (0) matrix at the fibre-matrix interface, and the nature of the fibre-matrix bonding mechanism, were studied via the use of focused ion beam (FIB) cross-sectioning, FIB imaging, scanning electron microscopy, and mechanical peel testing. The results show that the inclusion of the NiTi SMA fibres had a significant effect on the surrounding $\mathrm{Al}$ matrix microstructure during the UC process. Additionally, the fibre-matrix bonding mechanism appeared to be mechanical entrapment with the SMA surface showing signs of fatigue from the UC embedding process.
\end{abstract}

Keywords: ultrasonic consolidation, grain structure, aluminium 3003, shape memory alloy, smart structure, metal matrix composite

\section{INTRODUCTION}

The ultrasonic consolidation (UC) process (see Fig. 1) is a layer manufacturing process that was invented and patented by White (Solidica Inc., USA [1]). UC uses an ultrasonic welding (USW) system to deposit and bond metal foils layer by layer which are then contour milled using an integrated three-axis computer numerical controlled milling machine to create solid metal three-dimensional components [2].

There are several benefits of USW/UC, however, a key attribute of the USW/UC process is that a significant level of low temperature and high plastic flow can occur within the material being processed; previously

\footnotetext{
* Corresponding author: Wolfson School of Mechanical and Manufacturing Engineering, Loughborough University, Loughborough, Leicestershire LE11 3TU, UK.

email:r.j.friel@lboro.ac.uk
}

referred to as 'acoustic softening' [3]. This attribute can be and has been exploited to allow the embedding of active [4,5], passive [6], and optical fibres [7], as well as various other components $[\mathbf{5}, \mathbf{8}]$, within an $\mathrm{Al}$ matrix (refer to Fig. 1 steps (a), (b), and (c) for the embedding process).

Previous research was carried out, at Loughborough University, into the analysis of ultrasonically consolidated $\mathrm{Al}$ microstructures by Johnson $[\mathbf{9}, \mathbf{1 0}]$ and $\mathrm{Li}$ and Soar [11]. This work identified a deformation affected zone (DAZ) [9] close $(\leqslant 10 \mu \mathrm{m})$ to the UC foil-to-foil bond interface via the use of dual beam focused ion beam (DBFIB) etching and imaging. This DAZ was characterized by regions of reduced sub-grain sizes that gradually increased in size into the equiaxed structure of the native rolled Al foil. The sub-grain refinement identified by Johnson [10] was primarily attributed to direct contact between the sonotrode of the UC machine and the foil material surface; and has also been noted in traditional USW processes $[\mathbf{1 2}, \mathbf{1 3}]$. 


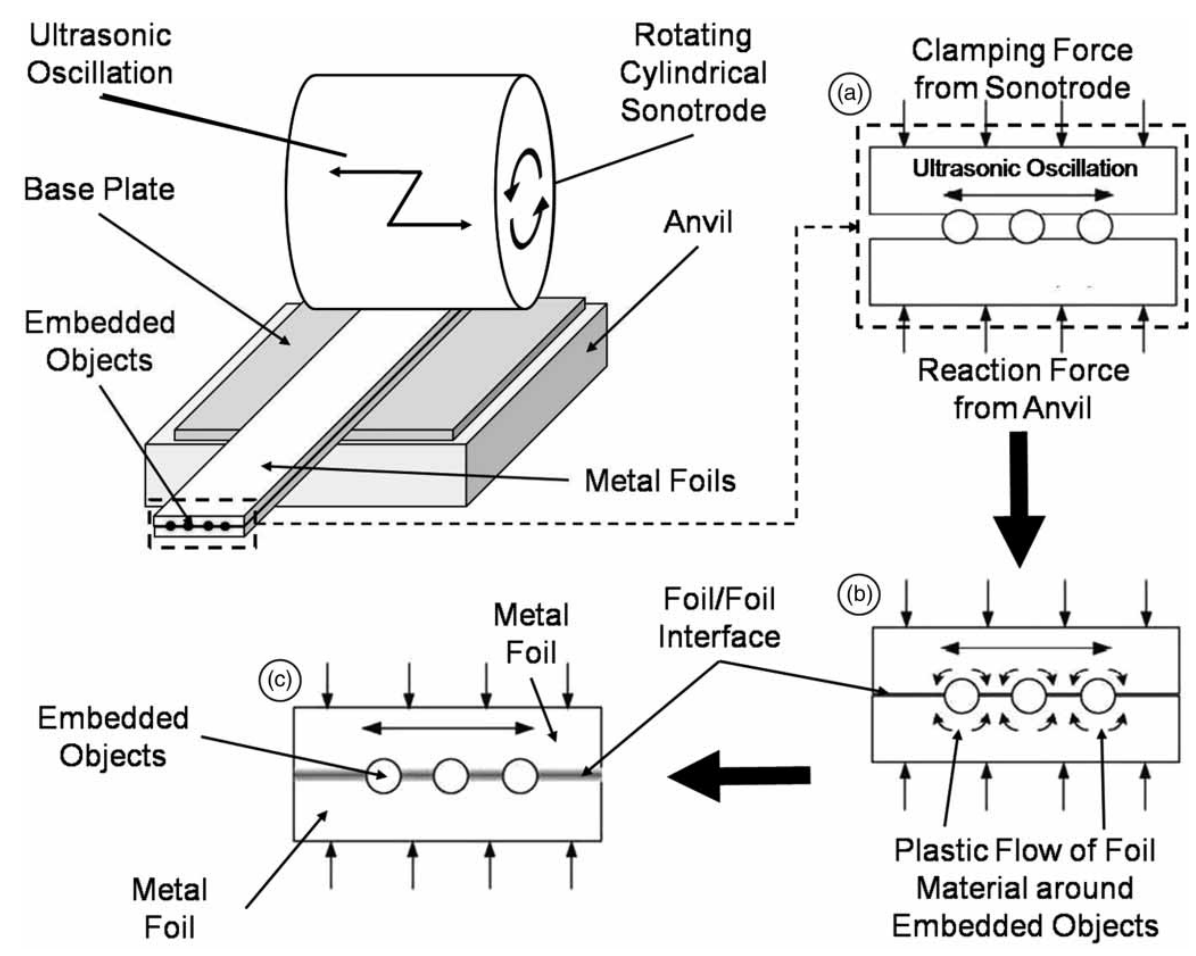

Fig. 1 Schematic diagram of the UC process for object embedment

Li and Soar [11] identified this sub-grain refinement, post-UC processing, around embedded fibres within an Al matrix and determined that this grain refinement resulted in a harder material than the unaffected bulk matrix. This sub-grain refinement is suggested to be fundamental to the solid state bond quality of components produced by the UC process; and may be a key mechanism in determining the quality of fibre encapsulation via UC.

This article was focused on determining if the subgrain refinement previously identified at the fibrematrix interface was due to the presence of the fibre during UC processing and not the residual sonotrode interaction with the matrix surface, prior to fibre embedding. Additionally, the fibre-matrix interface was analysed in-situ to help elucidate on the nature of the plastic flow around the shape memory alloy (SMA) fibre and the mechanism of fibre-matrix interfacial bonding. This was done through microscopic observation and physical experiments with results included from optical microscopy, focused ion beam (FIB) microscopy, and scanning electron microscopy (SEM); along with mechanical peel test results.

This new work was based on, and achieved due to, the past success at Loughborough University in utilizing the UC process to embed SMA fibres within an Al matrix. An SMA fibre has a recoverable deformation ability, which is referred to as the shape memory effect (SME). This allows a fibre to recover from approximately 5-8 per cent elongation when subjected to a material specific activation temperature [14]; which allows fully reversible extension and contraction of the fibre. SMA fibres rely on the intrinsic thermal properties of the fibre material and these properties can be adversely affected by some metal matrix composite (MMC) manufacturing methods. As UC is a relatively low temperature and low pressure manufacturing technique it is well suited to creating MMCs containing SMAs $[\mathbf{4}, \mathbf{5}]$.

A recent research route has been to explore the use of SMA fibres for actuation purposes within future smart structures [15-17]. Smart structures are structures that can monitor and then control/adapt to changing environments and/or structural conditions via the integration of sensing and actuation technologies [18]. The ultimate objective of this present work is to help further develop and understand the use of UC technology in the production of adaptive MMCs, which have been envisaged as a primary enabling technology in creating fully integrated 'smart' structures.

\section{METHODOLOGY}

\subsection{Materials}

The sample specimens were produced using aluminium 3003 (0) alloy, $100 \mu \mathrm{m}$ thickness and $24.5 \mathrm{~mm}$ width, foil with embedded $100 \mu \mathrm{m}$ diameter singlemode Flexinol $^{\mathrm{TM}}$ NiTi fibres (Dynalloy, Inc. USA). The chemical composition and mechanical properties of both the Al $3003(0)$ and NiTi fibres are stated in Table 1. 
Table 1 Mechanical properties and chemical composition of $\mathrm{Al} 3003$ (0) and Flexinol ${ }^{\mathrm{TM}}$ SMA fibres

\begin{tabular}{|c|c|c|c|}
\hline \multirow[b]{2}{*}{ Material property } & \multicolumn{2}{|c|}{ Flexinol $^{\mathrm{TM}} \mathrm{SMA}$} & \multirow[b]{2}{*}{$\mathrm{Al} 3003(0)$} \\
\hline & Austenitic & Martensitic & \\
\hline Density $\left(\mathrm{g} / \mathrm{cm}^{3}\right)$ & \multicolumn{2}{|c|}{6.45} & 2.73 \\
\hline Ultimate tensile strength (MPa) & 754 & 960 & 110 \\
\hline Tensile yield strength (MPa) & 100 & 560 & 41.4 \\
\hline Elongation at break (\%) & \multicolumn{2}{|c|}{15.5} & 30 \\
\hline Modulus of elasticity (GPa) & 28 & 75 & 68.9 \\
\hline Poisson's ratio & \multicolumn{2}{|c|}{0.3} & 0.33 \\
\hline Shear modulus (GPa) & 10.8 & 28.8 & 25 \\
\hline Melting temperature $\left({ }^{\circ} \mathrm{C}\right)$ & $1240-1310$ & $643-654$ & \\
\hline Composition (\%) & \multicolumn{2}{|c|}{ Ni (55), Ti (45) } & $\begin{array}{l}\mathrm{Al}(96.7-99), \mathrm{Mn}(1-1.5), \mathrm{Cu}(0.05-0.2), \mathrm{Fe}(\leqslant 0.7) \text {, } \\
\quad \mathrm{Si}(\leqslant 0.6), \mathrm{Zn}(\leqslant 0.1), \text { other }(\leqslant 0.15)\end{array}$ \\
\hline
\end{tabular}

A 'single-mode' NiTi SMA is a material in which martensitic to austenitic phase transformation occurs naturally when the material is heated to a predetermined, material specific, activation temperature $\left(70^{\circ} \mathrm{C}\right.$ in this instance). This phase transformation results in a dimensional change from the deformed geometry back to the original fibre geometry; previously stated as the SME. As the material can only recover to its original (austenitic phase) shape then some form of physical deformation is required to induce the martensitic phase (typically a tensile load applied axially).

\subsection{Sample production}

Each sample was produced on Loughborough University's Alpha UC machine (Solidica Inc., USA). This machine is a modified $3.3 \mathrm{~kW}$ seam welder, which has a rotating tool steel sonotrode that oscillates at a constant frequency of $20 \mathrm{kHz}$ (see Fig. 2). The equipment has been used in previous published work $[4,5,7,11,19-22]$, and has three key operating parameters; which can be individually set. These process parameters are welding speed $(\mathrm{mm} / \mathrm{s})$, contact

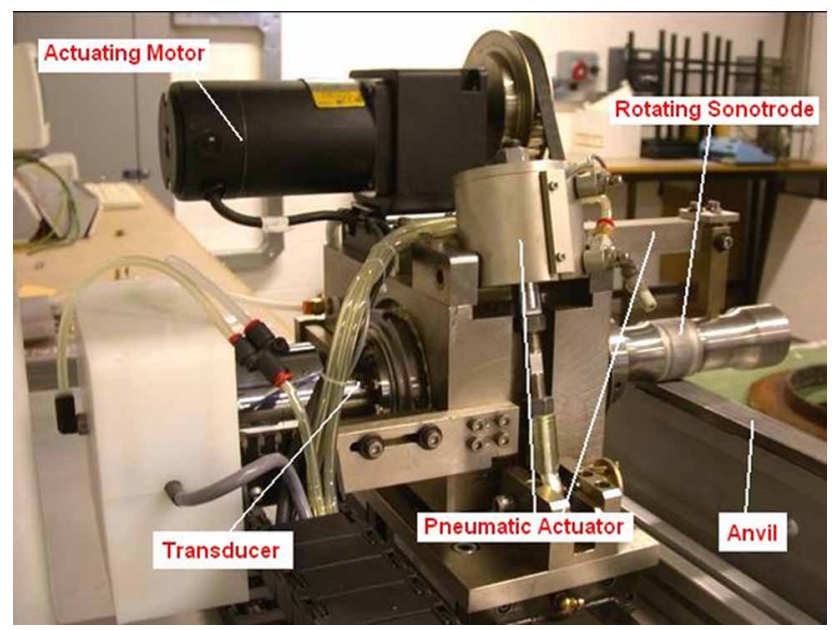

Fig. 2 Photo of an alpha UC machine used at Loughborough University pressure $(\mathrm{kPa})$, and amplitude of sonotrode oscillation $(\mu \mathrm{m})$.

The samples were produced by individually bonding (via UC) three $\mathrm{Al} 3003$ (0) foil layers to an $\mathrm{Al} 1050$ base plate $(150 \mathrm{~mm}$ long $\times 1.2 \mathrm{~mm}$ thick $\times 28 \mathrm{~mm}$ wide). Ten NiTi SMA fibres were then placed evenly across the consolidated foil width and restrained using a clamp to ensure accurate alignment during processing; after which another Al 3003 (0) foil layer was consolidated on top of the fibres to create the finished SMA/Al MMC. The processing parameters used to create the samples were: processing amplitude of $12.28 \mu \mathrm{m}$, contact pressure of $276 \mathrm{kPa}$, and a welding speed of $34.5 \mathrm{~mm} / \mathrm{s}$; these parameters were used due to previous research concluding that these parameters ensured a high level of fibre encapsulation.

\subsection{Optical analysis}

To determine the level of matrix plastic flow and void area at the fibre-matrix interface, optical microscopy was employed.

Samples were cross-sectioned, perpendicular to the longitudinal direction of the fibre, using a cutting disc. The sectioned SMA-Al MMC was then mounted in Buehler Varidur thermosetting polymer before being polished to a $0.1 \mu \mathrm{m} R_{\mathrm{a}}$ surface finish.

A Leica DM 6000 optical microscope with image capture was used to optically analyse and document the matrix-fibre interface of the polished samples. 12 polished samples were sectioned and analysed.

\subsection{Peel testing}

The peel testing was carried out in accordance with BS EN2243-2:1991. The peel testing allowed for bond quality to be quantitatively analysed by assessing a sample's average resistance to peeling. By comparing UC Al 3003 (0) samples without fibres to those that contained ten SMA fibres, it was possible to quantify the effect on peel strength that the fibres had and thus help in the understanding of the nature of the fibrematrix interface. Eighteen UC samples of Al 3003 (0) were compared with $18 \mathrm{Al} 3003$ (0)/SMA UC samples. 


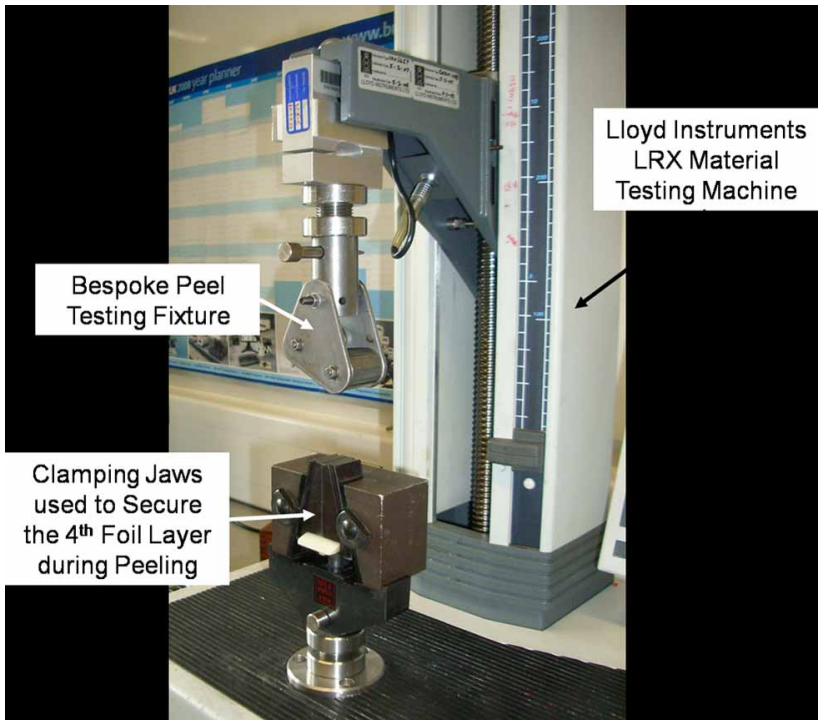

Fig.3 A Lloyd instruments LRX material testing machine with a bespoke peel testing fixture

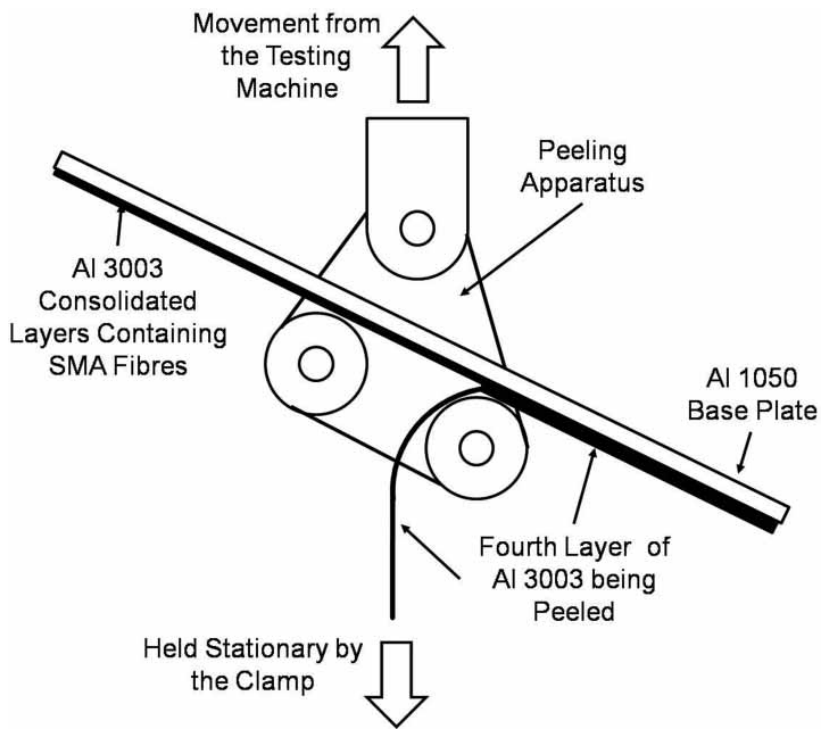

Fig. 4 Schematic of the sample mounting technique within the bespoke peel testing fixture

A bespoke peel testing fixture was attached to a Lloyd Instruments LRX material testing machine (Fig. 3), and used to peel samples that had been mounted as shown in Fig. 4. The unbonded foil length used to load the UC sample was $100 \pm 5 \mathrm{~mm}$ in length. The testing parameters used during the peel testing were to use a tensile loading speed of $50 \mathrm{~mm} / \mathrm{min}$ and the testing was set to stop when the peel force dropped to 10 per cent of the maximum load measured.

\subsection{SEM analysis}

The SEM analysis was performed using a Nova 600 NanoLab UHR FEG SEM/FIB machine (FEI Company,
Hillsboro, Oregon, USA). This machine can use an ultra high resolution (UHR) field emission gun (FEG) SEM for highly accurate sample visualization. After peel testing, samples were further sectioned and mounted on standard Al SEM pin stubs before being analysed with the SEM. The purpose of this analysis was to first investigate the 'trench' created by the SMA fibre, postUC processing, and fibre removal. Second, the SEM was used to identify areas of interest and suitability for the FIB cross-sectioning and analysis. This analysis was carried out using eight different samples.

\subsection{FIB analysis}

Grain structure analysis of the $\mathrm{Al}$ matrix adjacent to the fibre and also the fibre-matrix interface was performed by using a FIB to create a cross-section at an identified area. These areas were selected within and around the fibre trench. For grain structure analysis of the fibre-matrix interface the fibre was still present within the $\mathrm{Al}$ matrix so that a full structural analysis of both the $\mathrm{Al}$ and NiTi could be made simultaneously. This analysis was carried out using eight different samples.

Previous research [4] had not used DBFIB or UHR SEM analysis to observe the fibre-matrix interface. During the SEM and FIB analysis of the fibre-matrix interface, conducted in the present work, it was found that the fibre exhibited previously unidentified phenomena. As a cross-reference to the newly identified embedded SMA fibre structure both SEM and FIB analyses were performed on virgin (unembedded) SMA fibre structures.

\section{RESULTS}

\subsection{Matrix plastic flow around fibre}

Figures 5 and 6 show the level and intimacy of the plastic flow of the Al matrix around the SMA fibre after UC processing. The majority of the flow results in surface to surface contact between the fibre and matrix. For all the cross-sectioned optical micrographs, a calculation of void percentage (at $50 \times$ magnification) was performed at a radius of $60 \mu \mathrm{m}$ from the fibre centre; the averaged value was a void percentage of 4.62 (i.e. the fibre-matrix interface was approximately 95 per cent direct fibre-matrix interaction).

SEM analysis of the trench created by the SMA fibre showed that there was greater plastic deformation to the upper foil (consolidated after fibre placement) than the lower foil (consolidated prior to fibre placement). The lower foil-fibre interface had a greater level of void inclusion than the upper foil-fibre interface.

The inner trench surfaces had a visibly low surface roughness, which corresponded to the low surface roughness of the embedded SMA fibres. Small, 


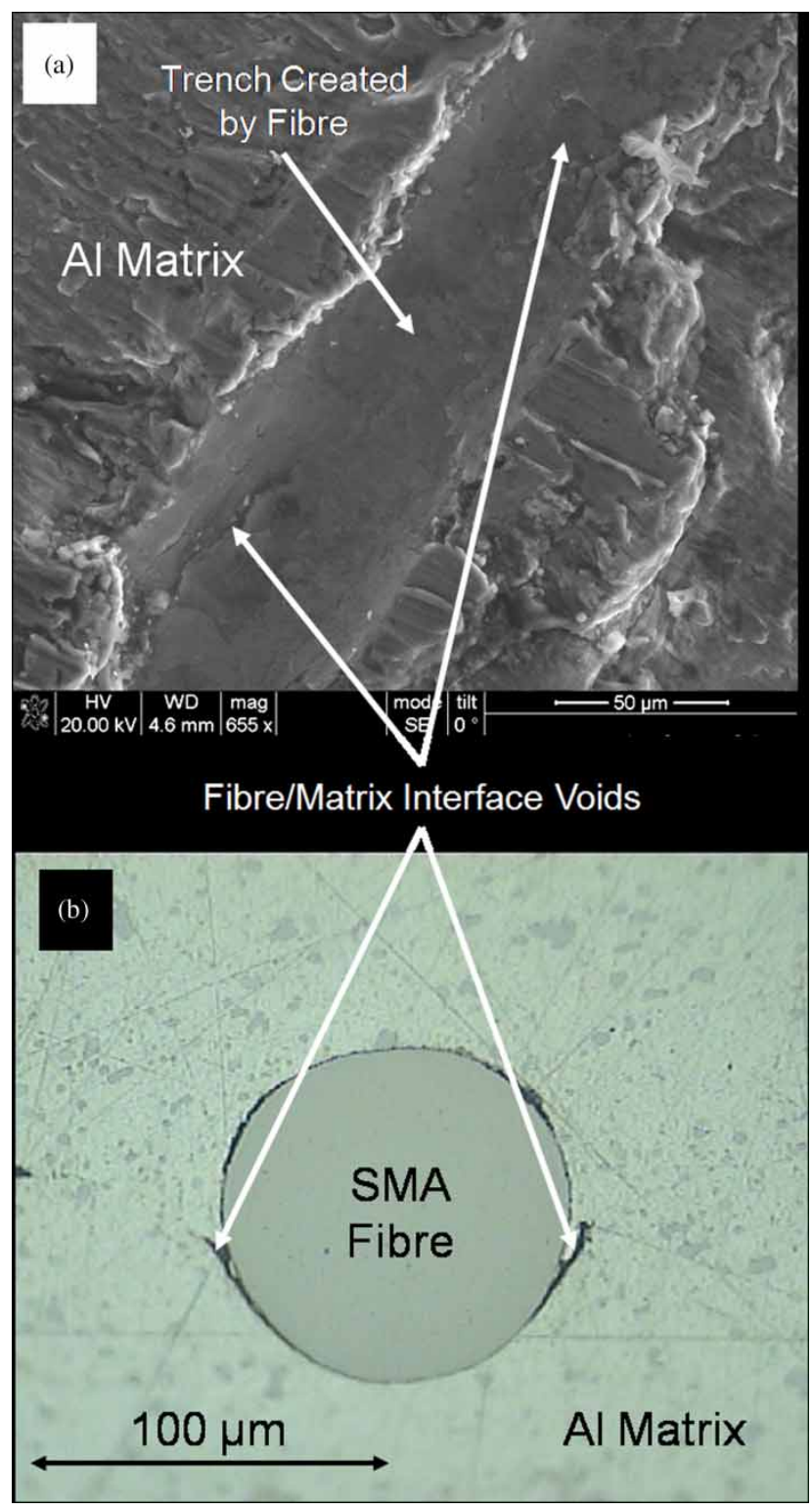

Fig. 5 Plastic flow of $\mathrm{Al} 3003$ (0) matrix around the SMA fibre: (a) SEM image of the 'trench' post-fibre removal showing high levels of matrix plastic deformation to encapsulate the fibre and (b) optical microscopy of cross-section showing porosity around the fibre

rougher, regions were visible that represented the void areas around the fibres.

\subsection{Grain and sub-grain structure}

The average grain size of the Al 3003 (0) was lower than pre-UC processing within $20 \mu \mathrm{m}$ of an embedded SMA fibre. The region $>20 \mu \mathrm{m}$ exhibited a grain structure comparable to the pre-UC Al 3003 (0) foil material (1-15 $\mu \mathrm{m}$ grain size). The highest levels of grain size reduction were observed at the top and bottom, relative to the normal force exerted by the sonotrode of the

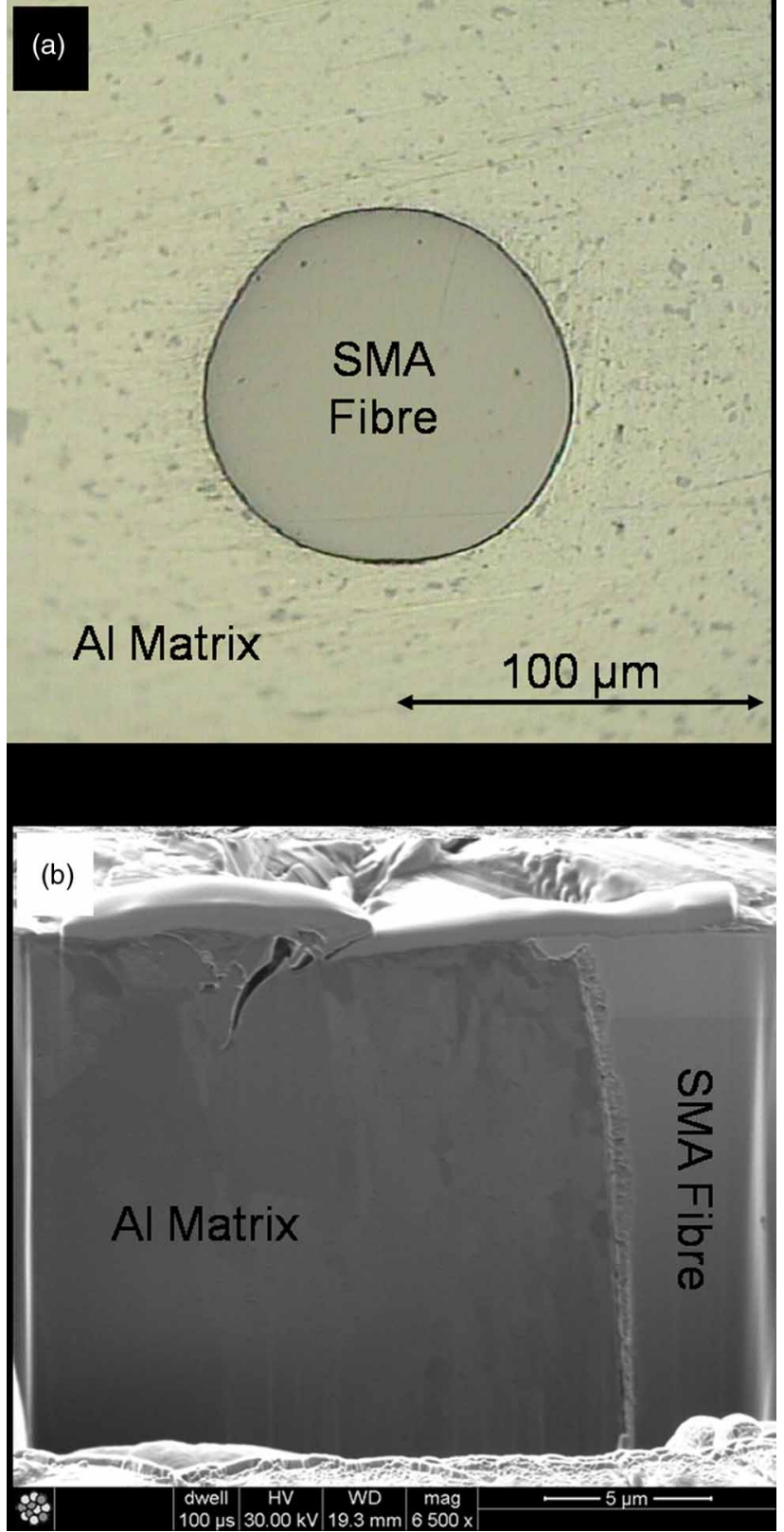

Fig. 6 Plastic flow of Al 3003 (0) matrix around the SMA fibre: (a) optical microscopy of cross-section showing minimal porosity around the fibre and (b) FIB image showing direct contact between the matrix and fibre

fibre-matrix contact. Figures 7 and 8 show the FIB and SEM images of the grain structures in close proximity to the SMA fibres.

There were regions of sub-grain refinement at and within close proximity $(<1 \mu \mathrm{m})$ of the embedded fibres and the sizes of these sub-grains varied from 1 to $2 \mu \mathrm{m}$.

\subsection{Fibre-matrix interface}

Figures 9 and 10 show the virgin fibre and fibrematrix interfaces at high magnification. A common 


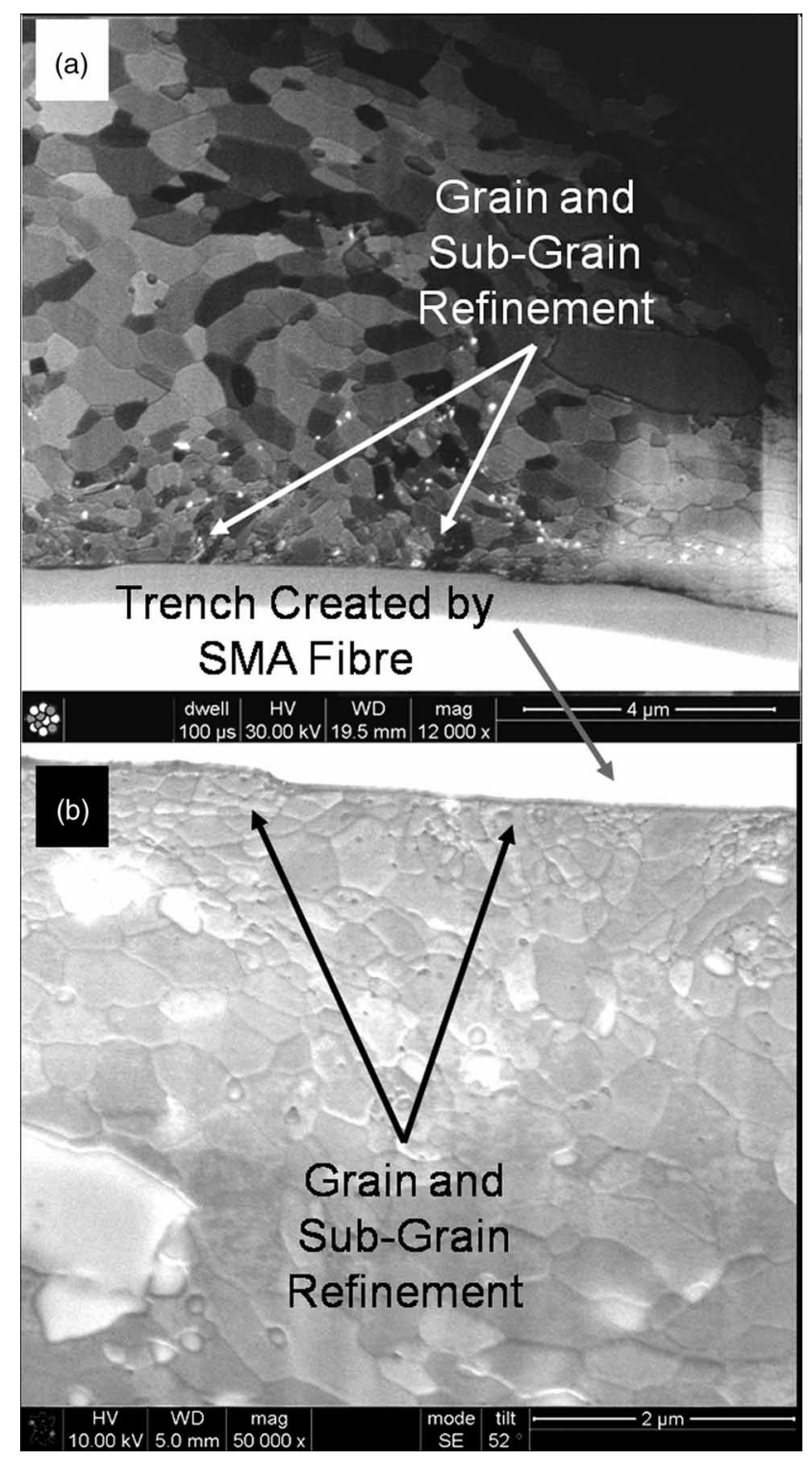

Fig. 7 Grain structure of the $\mathrm{Al} 3003$ (0) matrix around the SMA fibre: (a) FIB cross-section and image of the grain structure of the underside of the deposited foil post-fibre placement (upper foil layer) and (b) UHR SEM image (rotated $180^{\circ}$ ) showing (a) at higher magnification

characteristic that was exhibited by the SMA fibre was a high level of surface cracking to approximately $1 \mu \mathrm{m}$ depth into the SMA fibre surface. This cracking was also seen to cause larger scale deformation of the fibre surface (Fig. 10(b)), which was apparently exacerbated by the plastic flow of the $\mathrm{Al}$ matrix; this is an extreme case, however, this process was documented to a lesser extent in several other FIB images/crosssections. In all cross-sections there was no evidence of grain growth across the interface.

During peel testing the samples with embedded SMA fibres performed, on average, 11.27 per cent (average maximum peel force $=83.058 \mathrm{~N}$ ) lower than

\section{(a) Trench Created by SMA Fibre}
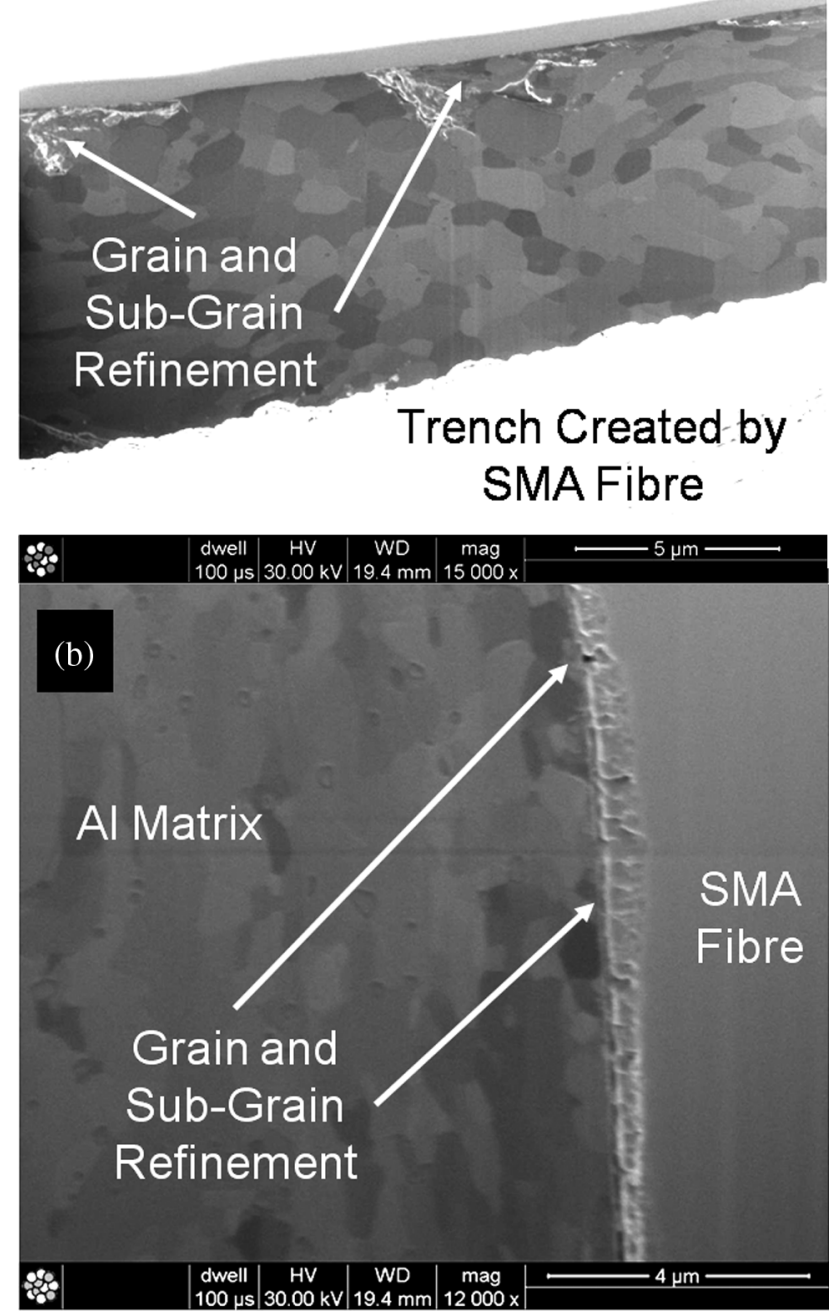

Fig. 8 Grain structure of the Al 3003 (0) matrix around the SMA fibre: (a) FIB cross-section and image of the grain structure of the upside of the deposited foil pre-fibre placement (lower foil layer) and (b) FIB cross-section and image of the grain structure of the upper foil matrix adjacent (left side) to the SMA fibre

UC Al 3003 (0) monolithic structures produced using the same processing parameters. Removal of the top foil layer allowed the fibres to move and fall from the matrix without the need for forceful separation.

\section{DISCUSSION}

\subsection{Matrix plastic flow and grain structure}

The plastic flow of the matrix was high without an apparent significant increase in the processing temperature, which corroborates with previous research $[4-8,11,19]$. This high level of plastic flow resulted in 


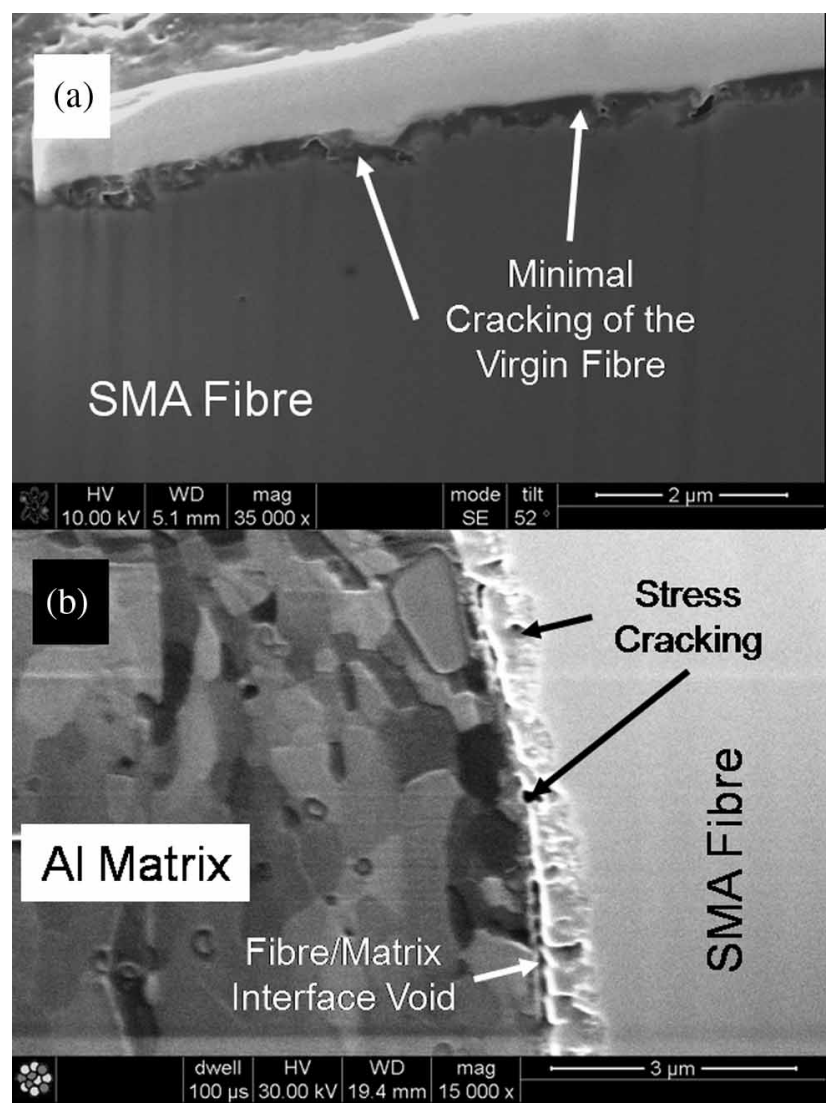

Fig. 9 Pre- and post-UC images of the SMA fibre: (a) FIB cross-section and UHR SEM image of the virgin (pre-UC) SMA fibre surface and (b) FIB cross-section and image of the stress cracking of the SMA fibre and void inclusions (post-UC)

an intimate contact between the fibre and the matrix with encapsulation being on average approximately 95 per cent complete. Although, there was this high level of encapsulation the majority of the plastic deformation occurred in the top foil layer that was being processed.

The direct sonotrode to foil contact resulted in the sonotrode imparting a roughened surface profile onto the foil surface. This uneven surface has been shown to include regions of highly refined sub-grain structure [10], which would present a harder material [11] for the fibre to embed into and thus potentially make the process more resistant to plastic flow and prone to void inclusion. During the deformation of this uneven, post-UC processed, surface a level of plastic flow does occur which appears to result in a high inclusion of surface oxides into the underlying fibre-matrix material (Fig. 8(a)). This oxide inclusion could alter the properties of the $\mathrm{Al} 3003$ (0) matrix and affect the mechanical performance of the MMC; as the oxide is a brittle material compared to the relatively ductile $\mathrm{Al}$ bulk matrix.

The grain structure in the vicinity $(<20 \mu \mathrm{m})$ of the embedded SMA fibre resulted in a significant level of

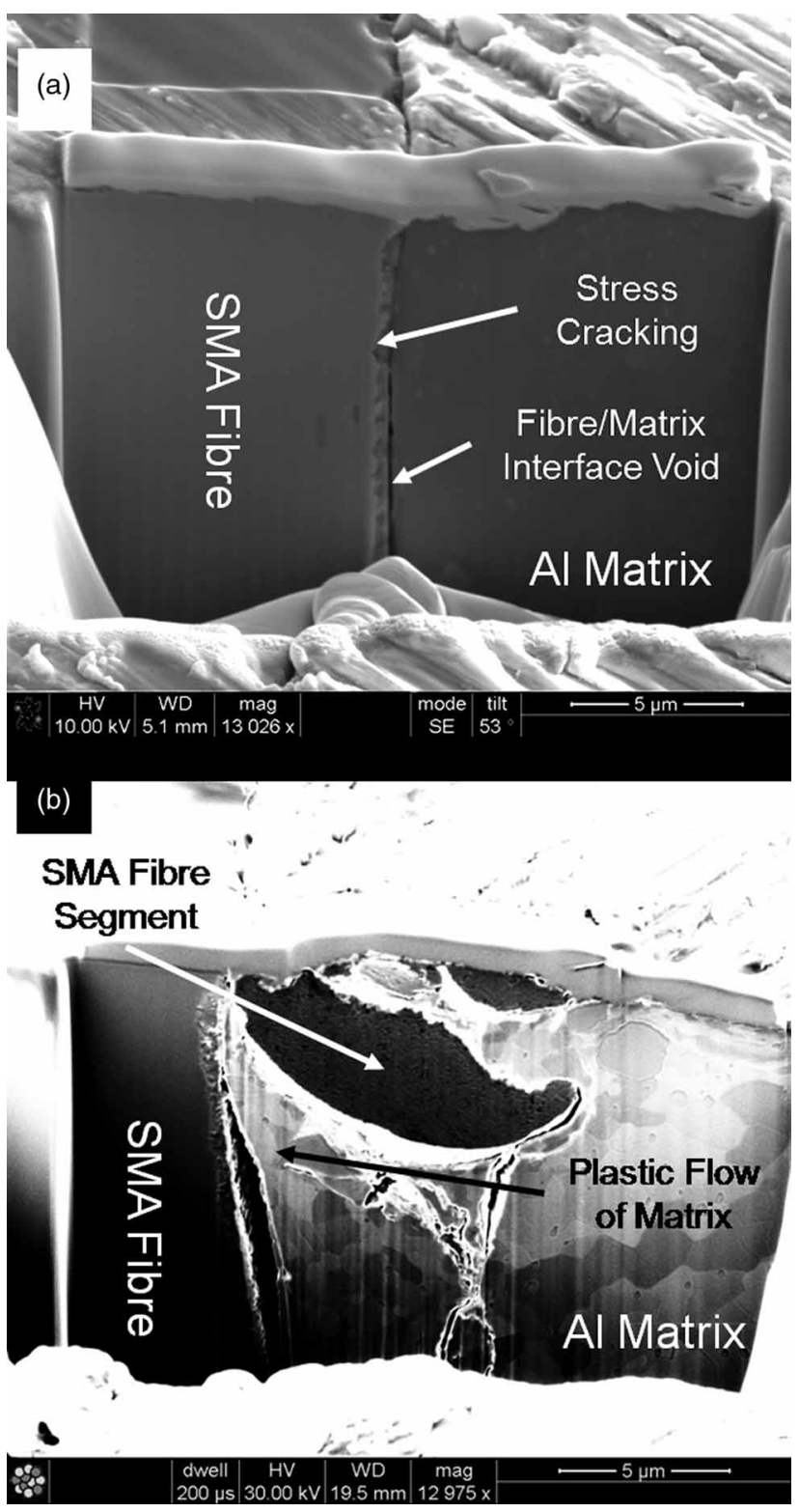

Fig. 10 Fibre matrix interface images between the $\mathrm{Al}$ 3003 (0) matrix and SMA fibre: (a) SEM micrograph of the FIB cross-section showing the specific damage and void inclusion at the fibre-matrix interface and (b) FIB cross-section and image showing the specific damage and then subsequent forceful matrix material flow at the fibre-matrix interface

grain refinement which is further proof to the findings of previous research [11]. The level and geometry of the refined matrix areas varied around the fibre suggesting the mechanism was not exactly the same for each region (i.e. above, below, and to the sides of the fibre).

At the fibre-matrix contact area at the bottom of the SMA fibre (Fig. 8(a)) to the previously deposited $\mathrm{Al}$ layer; the grain refinement was in deformed 'pockets' that appeared random in location with regards 
to the SMA fibres. These pockets were likely a result of the previous direct sonotrode to surface contact, which was shown to create regions of highly refined sub-grain 'peaks' on the surface of the deposited $\mathrm{Al}$ foil [10]. A possible scenario is that when the fibre is forced onto this previously deposited, harder foil by the sonotrode, the resultant reaction force and ultrasonic energy causes the greater embedding, of the fibre, into the upper, softer layer of foil. Therefore the embedding process is not a 50:50 split, in terms of embedding depth, between the upper and lower foil layers. These hard 'peaks' also appear to be forced back into the surrounding matrix material by the SMA fibre and this, as previously mentioned, results in a relatively high level of oxide and void inclusion, but with little grain refinement to the surrounding area. However, this forceful insertion of the peaks does appear to result in a relatively large realignment of the surrounding grain structure and flow direction.

Regions to the left and right of the fibre exhibit a degree of grain refinement with apparent sub-grain pockets (Figs 8(b), 9(b), and 10(b)). These sub-grain pockets, to the left and right of the fibre, were only identified in the previously deposited foil and not in the upper foil layer. These pockets could be the hard 'peak' structures, caused by direct sonotrode contact, that were mentioned previously. These sub-grain regions in the lower foil and the surrounding grain structure showed the same flow patterns as the area below the SMA fibre; this could be due to the same forcing of the sub-grain peak back into the matrix.

From the images of the trench left by the embedded fibre (Fig. 6(a)), it is apparent that although the fibres were under tension they exhibited a degree of nonlinearity in their lay. This may be due to the oscillatory motion of the sonotrode resulting in fibre movement during UC; however, there is a possibility that the hard peak regions of the previously deposited foil result in a 'diversion' of the fibre into the softer troughs of the previously processed foil surface. This would result in some distortion to the lay of the fibre when it is in contact with the harder peak region. This effect may have implications in the geometric accuracy of MMCs produced via UC; the movement of fibres during processing can make alignment difficult and a method with which to prevent this movement would be desirable if UC is to be made more viable as an MMC manufacturing method.

The matrix region above the SMA fibre exhibited a highly refined sub-grain structure that followed a conical shape directly above the fibre (Figs 7(a) and (b)). The level of grain refinement reduced as the matrix flowed around the fibre towards the foil to foil interface. This region of the foil was never in contact with the sonotrode and/or previously deposited foil; therefore this sub-grain refinement is likely to be caused by the fibre-matrix interaction in the presence of high levels of ultrasonic acoustic energy. This effect shows similar results to the identified sonotrode to foil interaction and suggests that ultrasonic acoustic energy transmission through the foil material is sufficiently high to create the high levels of sub-grain refinement at the foil to fibre interface.

In addition to the identified sub-grain regions above the fibres a relatively high level of oxide inclusion within the matrix was witnessed. This oxide inclusion within the matrix suggests that there may be a sufficiently high level of grain mobility that surface oxides are included and dispersed among the grain boundaries of the matrix material; however, further work would be required to ensure this was the case.

\subsection{Fibre-matrix interface}

The fibre-matrix interface was approximately 95 per cent matrix-to-fibre direct contact, on average. Although this contact was metal to metal it appears, from nano-scale investigation, that there is no grain growth across the interface (Figs $8(\mathrm{~b})$ and $9(\mathrm{~b})$ ). In addition to this, the UC process had an apparent fatiguing effect on the surface of the SMA fibre. This was represented by small scale cracking of the fibre surface to a depth of approximately $1 \mu \mathrm{m}$. Although for the majority of the images taken this cracking was apparently a small surface effect, in some instances this cracking had led to sections of the fibre being sheared off from the bulk of the fibre. This shearing was coupled by infiltration of the matrix material behind the fragment and towards the fibre. This suggests that the fracturing occurs early enough in the UC process to allow for the fibre segment to move and for the matrix to have time to flow behind the segment (i.e. this fracturing has occurred during UC processing, not post-processing). From analysis the matrix material that flowed behind the segment exhibited the same sub-grain structure and oxide inclusion that was found at the bottom foil to fibre interface. A reason for this may be that the hard area of the matrix (the sub-grain refined peak), is increasing the fatigue and maximum stress to the surface of the fibre and has helped cause this fracturing of the fibre (i.e. these hard peaks are acting as an extra abrasive agent during the UC processing). Li and Soar [11] suggested that some high hardness results for the area around a SiC fibre in a UC $\mathrm{Al}$ matrix maybe be due to dispersion of $\mathrm{TiB}_{2}$ particles at the fibre-matrix interface. Although the SMA fibres are not purposefully coated, they do have an unavoidable oxide layer on the surface, the same process that has dispersed fragments of the $\mathrm{TiB}_{2}$ may also have caused the cracking and then separation of external SMA fibre fragments in this instance. $\mathrm{The}^{\mathrm{TiB}} \mathrm{B}_{2}$ particles were a coating on the $\mathrm{SiC}$ fibres and may have been dispersed in a similar way to the exterior of the SMA fibres in the current work. This highly erosive mechanism of ultrasonic work hardening and hard matrix material 
pockets may also help explain the damage caused to fibres during UC in other research [7].

The inclusion of SMA fibres into the UC Al matrix reduced the peel strength of the samples, for this particular set of loading conditions. A reduction of 11.27 per cent was observed for a fibre volume fraction of approximately 3.2 per cent (i.e. ten fibres). This showed that the inclusion of fibres, in this instance, hindered UC bonding and suggests that the matrix-to-fibre bonding was weaker than matrix-to-matrix bonding, or was entirely non-existent. This identification of weak matrix-to-fibre bonding was furthered by the observation that a lack of force was required to remove fibres from a peeled sample. This microstructural and mechanical evidence implies that the fibre-matrix bonding mechanism was mechanical entrapment by the matrix around the fibre as opposed to a chemical or atomic diffusion type bond. This supports the suggestions of previous research [23]. Because of the fibres not bonding to the matrix, the inclusion of fibres reduces the area of matrix-to-matrix contact and appears to act in a similar way to voids within the bond area. The use of fibre materials increased the plastic flow of the matrix resulting in greater matrix-tomatrix interaction which could possibly increase the matrix-to-matrix bond strength. Therefore, the apparent reduction in the peel strength in this investigation may not necessarily suggest a reduction in the overall matrix bonding strength.

\section{CONCLUSIONS AND FUTURE WORK}

The apparent bonding between NiTi SMA fibres and an Al 3003 (0) matrix during UC processing was relatively weak and likely to be mechanical entrapment of the fibre within the metal matrix. The fibres also exhibited a degree of lateral movement post-UC processing. This has reaching implications in terms of creating accurate, mechanically robust, fibre containing MMCs via UC. A method by which to maximize matrix flow around the fibre and to accurately align fibres would be desirable to reduce the observed weakening effect of the fibre material on the matrix strength while improving the accuracy of the MMC produced by the UC process. This maximization of flow could potentially be achieved by pre-created 'trenches' in which to lay the fibres. This could ensure maximum encapsulation by the matrix material and minimum fibre lateral movement during UC. The creation of these trench structures via the use of a fibre laser is currently being investigated by the authors.

Coating of the fibres, prior to UC, with a material known to bond well with the matrix during UC may also improve the mechanical performance of UC MMCs. A method by which this may be achieved is through vapour deposition onto the fibre material prior to embedding via UC; this would help avoid the loss of the SME of the SMA through aggressive thermal cycling. A protective jacket that facilitates mechanical interlocking with the matrix material could also be utilized.

The embedded fibres appear to have a sonotrodelike effect on the surrounding metal matrix by reducing the grain size and inducing work hardening during UC processing. During fibre embedding via UC the introduction of fibre material could be utilized to create a work hardened internal structure to the metal matrix. The strategic use of this work hardening effect could be used to create MMCs that are very hard, compared to the raw processing foil, and/or the creation of functionally graded MMCs (i.e. hard in desired areas).

The DBFIB process is still relatively new and its usefulness in identifying micro- and nano-scale effects around the fibre post-UC was invaluable. Future use of the DBFIB cross-sectioning procedure and imaging could significantly increase the understanding of the micro/nano-scale effects many manufacturing processes have on the raw materials used for production. Future work by the authors will continue to use the DBFIB equipment to investigate the effect of the SMA fibres on the microstructure of the matrix material during UC processing.

The UC process coupled with hard areas of sub-grain matrix can damage embedded SMA fibres through a combination of surface cracking and plastic flow. The authors are investigating the functionality of embedded, via UC, SMA fibres to determine any effect of the UC process on the SME of the SMA fibres. The SMA fibres will be thermally and mechanically analysed pre-, during, and post-activation, after embedment into an $\mathrm{Al}$ matrix via $\mathrm{UC}$, to determine if the fibrematrix interface is sufficient for creating durable smart structures. The SMA fibres must be functional if UC is to be fully utilized as a manufacturing process for creating unique smart structures through the use of MMCs.

\section{ACKNOWLEDGEMENT}

This work was supported by the Engineering and Physical Science Research Council. The authors would like to acknowledge Dr Geoff West of the Department of Materials at Loughborough University for help with the DBFIB analysis.

(C) Authors 2010

\section{REFERENCES}

1 White, D. Ultrasonic object consolidation. US Pat 6519500, 11 February 2003.

2 White, D. Ultrasonic consolidation of aluminium tooling. Adv. Mater. Process., 2003, 161, 64-65. 
3 Langenecker, B. Effects of ultrasound on deformation characteristics of metals. IEEE Trans. Sonics Ultrasonics, 1966, 13, 1-8.

4 Kong, C. Y., Soar, R. C., and Dickens, P. M. Ultrasonic consolidation for embedding SMA fibres within aluminium matrices. Compos. Struct., 2004, 66(1-4), 421-427.

5 Kong, C. Y. Investigation of ultrasonic consolidation for embedding active/passive fibres in aluminium matrices. $\mathrm{PhD}$ Thesis, Wolfson School of Mechanical and Manufacturing Engineering, Loughborough University, UK, 2005.

6 Yang, Y., Janaki Ram, G. D., and Stucker, B. E. An experimental determination of optimum processing parameters for $\mathrm{Al} / \mathrm{SiC}$ metal matrix composites made using ultrasonic consolidation. J. Eng. Mater. Technol., 2007, 129, 538-549.

7 Kong, C. Y. and Soar, R. C. Method for embedding optical fibres in an aluminium matrix by ultrasonic consolidation. Appl. Opt., 2005, 44, 63256333.

8 Mou, C., Saffari, P., Li, D., Zhou, K., Zhang, L., Soar, R. C., and Bennion, I. Smart structure sensors based on embedded fibre Bragg grating arrays in aluminium alloy matrix by ultrasonic consolidation. Meas. Sci. Technol., 2009, 20, 034013.

9 Johnson, K. Interlaminar subgrain refinement in ultrasonic consolidation. PhD Thesis, Wolfson School of Mechanical and Manufacturing Engineering, Loughborough University, UK, 2008.

10 Johnson, K. and Higginson, R. Formation of nano-grains during biaxial high frequency fully reversed loading. In Proceedings of the Materials Science and Technology Conference, Detroit, USA, 2007.

11 Li, D. and Soar, R. C. Plastic flow and work hardening of Al alloy matrices during ultrasonic consolidation fibre embedding process. Mater. Sci. Eng. A, 2008, 498(1-2), 421-429.

12 Allameh, S. M., Mercer, C., Popoola, D., and Soboyejo, W. O. Microstructural characterisation of ultrasonically welded aluminium. J. Eng. Mater. Technol., 2005, 127, 65-74.

13 Brodyanski, A., Born, C., and Kopnarski, M. Nm-scale resolution studies of the bond interface between ultrasonically welded Al-alloys by an analytical TEM: a path to comprehend bonding phenomena? Appl. Surf. Sci., 2005, 252, 94-97.

14 Ortin, J. and Planes, A. Thermodynamics of thermoelastic martensitic transformations. Acta Metall., 1989, 27, 1433-1441.

15 Bannuru, T. and Armstrong, W. D. Observed dependencies of the large thermal-compressive response of a NiTi shape-memory alloy fibre aluminium metal matrix composite on maximum tensile strain imposed during a preceding room-temperature tensile process. Metall. Mater. Trans. A, 2004, 35A, 1403-1406.

16 Armstrong, W. D. and Lorentzen, T. Large self-thermalplastic deformation in a NiTi shape-memory alloy fibreactuated aluminium metal-matrix composite. Metall. Mater. Trans. A, 2002, 33A, 3535-3540.

17 Gilat, R. and Aboudi, J. Dynamic response of active composite plates: shape memory alloy fibres in polymeric/metallic matrices. Int. J. Solids Struct., 2004, 41, 5717-5731.

18 Balta, J. A., Bosia, F., Michaud, V., Dunkel, G., Botsis, J., and Månson, J.-A. Smart composites with embedded shape memory alloy actuators and fibre Bragg grating sensors: activation and control. Smart Mater. Struct., 2005, 14, 457-465.

19 Kong, C. Y. and Soar, R. C. Fabrication of metal-matrix composites and adaptive composites using ultrasonic consolidation process. Mater. Sci. Eng. A, 2005, 412(1-2), $12-18$.

20 Kong, C. Y., Soar, R. C., and Dickens, P. M. Characterisation of aluminium alloy 6061 for the ultrasonic consolidation process. Mater. Sci. Eng. A, 2003, 363, 99-106.

21 Kong, C. Y., Soar, R. C., and Dickens, P. M. A model for weld strength in ultrasonically consolidated components. Proc. IMechE, Part C: J. Mechanical Engineering Science, 2005, 219(C1), 83-91. DOI: 10.1243/095440605X8315.

22 Kong, C. Y., Soar, R. C., and Dickens, P. M. Optimum process parameters for ultrasonic consolidation of 3003 aluminium. J. Mater. Process. Technol., 2004, 146, 181-187.

23 Yang, Y., Janaki Ram, G. D., and Stucker, B. E. Bond formation and fiber embedment during ultrasonic consolidation. J. Mater. Process. Technol., 2009, 209(10), 4915-4924. 